\title{
Effect of Electric Field Uniformity on Streamer and Breakdown Characteristics in a Gas-to-Liquid Oil under Positive Lightning Impulse
}

DOI:

10.1109/ICHVE49031.2020.9279486

\section{Document Version}

Accepted author manuscript

Link to publication record in Manchester Research Explorer

Citation for published version (APA):

Yu, H., Liu, Q., Wang, Z., Krause, C., \& Hilker, A. (2020). Effect of Electric Field Uniformity on Streamer and Breakdown Characteristics in a Gas-to-Liquid Oil under Positive Lightning Impulse. In 2020 IEEE International Conference on High Voltage Engineering and Application https://doi.org/10.1109/ICHVE49031.2020.9279486

Published in:

2020 IEEE International Conference on High Voltage Engineering and Application

\section{Citing this paper}

Please note that where the full-text provided on Manchester Research Explorer is the Author Accepted Manuscript or Proof version this may differ from the final Published version. If citing, it is advised that you check and use the publisher's definitive version.

\section{General rights}

Copyright and moral rights for the publications made accessible in the Research Explorer are retained by the authors and/or other copyright owners and it is a condition of accessing publications that users recognise and abide by the legal requirements associated with these rights.

\section{Takedown policy}

If you believe that this document breaches copyright please refer to the University of Manchester's Takedown Procedures [http://man.ac.uk/04Y6Bo] or contact uml.scholarlycommunications@manchester.ac.uk providing relevant details, so we can investigate your claim.

\section{OPEN ACCESS}




\section{Effect of Electric Field Uniformity on Streamer and Breakdown Characteristics in a Gas-to-Liquid Oil under Positive Lightning Impulse}

\author{
Haichuan $\mathrm{Yu}$ \\ Department of Electrical and \\ Electronic Engineering \\ The University of Manchester \\ Manchester, UK \\ haichuan.yu@ postgrad.manchester.ac.uk \\ Christoph Krause \\ Weidmann Electrical Technology AG \\ Rapperswil, Switzerland \\ christoph.krause@weidmann- \\ group.com
}

\author{
Qiang Liu* \\ Department of Electrical and \\ Electronic Engineering \\ The University of Manchester \\ Manchester, UK \\ qiang.liu@manchester.ac.uk \\ Andree Hilker \\ Shell Global Solutions (Deutschland) - \\ $\mathrm{GmbH}$ \\ Hamburg, Germany \\ andree.hilker@shell.com
}

\author{
Zhongdong Wang \\ Department of Electrical and \\ Electronic Engineering \\ The University of Manchester \\ Manchester, UK \\ zhongdong.wang@manchester.ac.uk
}

\begin{abstract}
This paper presents an experimental study on the streamer characteristics of a gas-to-liquid (GTL) oil in a semiuniform field under positive lightning impulse. To realize the semi-uniform field, a plane-needle-plane electrode geometry was applied. The needle-plane geometry, non-uniform field, with the same oil gap distance was also employed for comparison. The streamers propagate farther when the applied voltage increases in both fields, however compared to the nonuniform field, the streamers in semi-uniform field are constrained along the axial direction with less side branches. Additionally, the streamer initiation voltage and breakdown voltage are higher in semi-uniform field while the streamer propagation is facilitated compared to the non-uniform field. Meanwhile, two more electrode geometries with different field uniformities were used to measure the streamer initiation voltages and breakdown voltages in the GTL oil. The results were also compared with conventional mineral oil, and GTL oil shows similar streamer initiation voltages and breakdown voltages as the mineral oil in the present investigation, which provides additional reference for the application of GTL oil in power transformers.
\end{abstract}

Keywords-GTL oil, semi-uniform field, non-uniform field, streamer characteristics, initiation voltage, breakdown voltage

\section{INTRODUCTION}

Power transformer is one of the most essential equipment in power networks. The solid-liquid insulation system is generally applied in power transformer. The most popular insulating liquid is petroleum-based mineral oil which has been employed for more than one century due to its excellent dielectric performance and high reliability in operation. In recent years, the Gas-to-Liquid (GTL) technology is applied to produce hydrocarbon based transformer oils. Compared with the conventional mineral oils, GTL based transformer oil is purified and virtually sulphur free [1], which is helpful to keep the health of transformers.

As for a transformer liquid, it is important to fully understand its discharge and breakdown properties. Besides AC stress, the dielectric characteristics of insulating liquids under lightning impulse are essential as well since the power transformer may be exposed to the transient overvoltage induced by lightning strike during their operation. Lightning impulse strength is also regarded as one of the insulation design criteria for power transformers according to standard IEC 60076-3 [2]. However, at present, the published studies of GTL oil under lightning impulse are mainly focused on the streamer and discharge behaviours with needle-plane (NP) or needle-sphere electrode geometries whose electric fields are highly non-uniform [3-8]. Such a non-uniform electric field is avoided to utmost in power transformers. To simulate the semi-uniform field which is closer to what exists in the transformer, a plane-needle-plane (PNP) electrode geometry was introduced.

A few studies about the discharge and breakdown characteristics in semi-uniform electric field have been done in conventional mineral oils and ester liquids under lightning impulse [9-11]. It was found that the electrode for the PNP configuration weakens the electric field towards radial direction and makes the electric field more uniform, which further facilitates the streamer propagation compared to the needle-plane non-uniform field [9, 12].

In this paper, the streamer characteristics of a GTL oil in semi-uniform electric field were investigated under positive lightning impulse. The streamer initiation voltages and breakdown voltages in the GTL oil under different electrode geometries were also tested and compared with conventional mineral oil.

\section{EXPERIMENTAL DESCRIPTION}

\section{A. Experimental Setup}

The experimental setup is illustrated in Fig. 1. A DC power generator and a fast high voltage solid-state transistor switch are applied to generate the positive lightning impulse. A Schlieren system is built to visualize the streamer initiation and propagation characteristics under the help of a high-speed camera SIM16 which contains 16 high resolution intensified CCD sensors. The fixed lens installed on the camera is a commercial Sigma $105 \mathrm{~mm} \mathrm{f} / 2.8$ DG Macro lens. During the operation, the light was generated by a flash head with the power of $500 \mathrm{~J}$, and then after passing through the mirrors, lens and samples, the light beam is captured by the camera. 16 


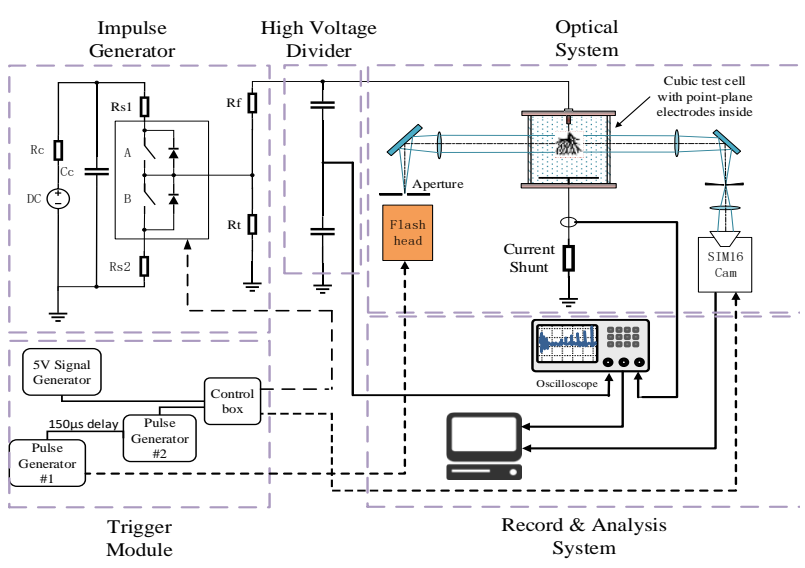

Fig. 1. Experimental setup for streamer characteristics investigation under positive lightning impulse [9].

successive frames were captured with the fixed exposure time of $1 \mu \mathrm{s}$ in the experiments. A triggering module is also constructed to trigger the lightning impulse generator and the Schlieren system to register the streamer morphology with high quality. The current signal is measured by a $10 \Omega$ noninductive current shunt at the earth side of the sample. Both the applied voltage waveform and the current signal are recorded by the oscilloscope. More details about the experimental setup can be seen in [9].

\section{B. Electrode Geometries and Field Enhancement Factors}

The GTL oil is contained in a 2 litres transparent PMMA made test cell with PNP or NP electrodes installed inside. The electrode geometries are shown in Fig. 2. The diameter of the brass plane electrode is $50 \mathrm{~mm}$. The commercial medical stainless steel needle with tip radius $r_{p}$ of around $10 \mu \mathrm{m}$ is employed as the needle electrode. The gap distance $d$ from needle tip to opposite plane electrode is fixed at $10 \mathrm{~mm}$. For PNP electrode geometry, the needle protrusion $L$ from needle tip to back plane electrode is fixed at $8 \mathrm{~mm}$. During experiment, the needle will be replaced after no more than 3 breakdowns.

When measuring the streamer initiation voltage and breakdown voltage in GTL oil, 2 more NP electrode geometries are applied. The gap distances are $3.56 \mathrm{~mm}$ and $8.20 \mathrm{~mm}$. The electric fields of different electrode geometries were carefully calculated through the finite element analyses software COMSOL Multiphysics ${ }^{\circledR}$. To indicate their field uniformity distinctions, the field enhancement factor (abbreviated as field factor in the following content) was applied and calculated [11]. Totally, four electrode geometries with different field factors are shown in TABLE I.

\section{Sample Preparation}

The GTL oil, Diala S4 ZX-I, was tested in this study. The insulating oil was filtered by $0.2 \mu \mathrm{m}$ membrane filters first. Then, the oil was dehydrated by purging clean dry nitrogen into the oil. The water content was controlled lower than 15 ppm during the whole test. Before test, the oil sample was also degassed. After 20 breakdowns, the oil was filtered again to make sure the oil sample was clean enough during the test.

\section{RESULTS AND DISCUSSION}

The streamer propagation morphology and characteristics in the GTL oil were compared between the non-uniform field and the semi-uniform field. Additionally, to measure the streamer imitation voltage and breakdown voltage, the applied

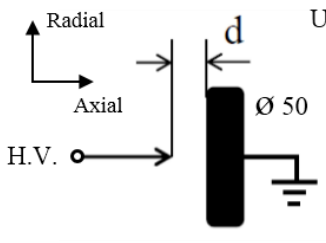

(a)

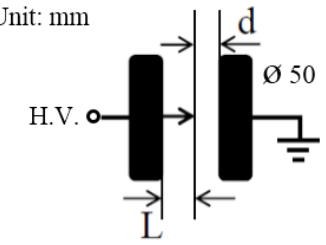

(b)
Fig. 2. Electrode geometries for different field uniformities: (a) NP nonuniform geometry; (b) PNP semi-uniform geometry. L and d indicate needle protrusion length and oil gap distance, respectively.

TABLE I. ELECTRODE GEOMETRIES WITH DIFFERENT FIELD FACTORS

\begin{tabular}{|c|c|c|c|}
\hline $\begin{array}{c}\text { Electrode } \\
\text { Geometry }\end{array}$ & $\begin{array}{c}\text { Gap, } \boldsymbol{d} \\
(\mathbf{m m})\end{array}$ & $\begin{array}{c}\text { Needle Protrusion } \\
\boldsymbol{L}, \mathbf{( m m})\end{array}$ & $\begin{array}{c}\text { Field Factor } \boldsymbol{f} \\
\text { (COMSOL) }\end{array}$ \\
\hline NP & 3.56 & - & 107 \\
\hline PNP & 10.00 & 8 & 158 \\
\hline NP & 8.20 & - & 209 \\
\hline NP & 10.00 & - & 246 \\
\hline
\end{tabular}

voltage was started from $70 \%-80 \%$ of the expected initiation voltage or breakdown voltage, then increased with $0.5 \mathrm{kV}$ or $1 \mathrm{kV}$ per step. Under each voltage step, only one shot impulse was applied. A minimum 1 minute interval time was used between two successive impulses. After breakdown, a minimum 15 minutes relaxing time was applied. Under each condition, 20 breakdown events were recorded in total.

\section{A. Streamer Propagation Characteristics}

Typical positive streamers in non-uniform field and semiuniform field under different applied voltages are shown in Fig. 3 and Fig. 4, respectively. The photos show the final state of the streamer under each impulse shot. It can be seen clearly that the streamers are initiated from the needle tip, the highest field position, and mainly propagated to the opposite plane electrode. Meanwhile, the streamers propagate farther with increasing applied voltages. With the non-uniform field, there are typically 2 or 3 main branches, different from the streamer shapes with the semi-uniform field, where there are less main branches propagating straightforward to the opposite electrode. The streamers become much narrower and constrained along the axial direction with less side offshoots in semi-uniform field. The axial and radial directions are defined in Fig. 2.

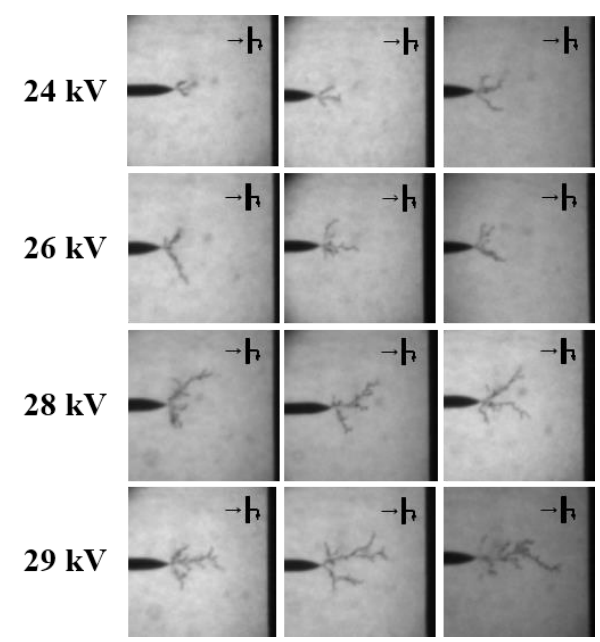

Fig. 3. Typical positive streamer morphologies in non-uniform field under different voltages, $\mathrm{d}=10 \mathrm{~mm}, \mathrm{r}_{\mathrm{p}}=10 \mu \mathrm{m}$. 


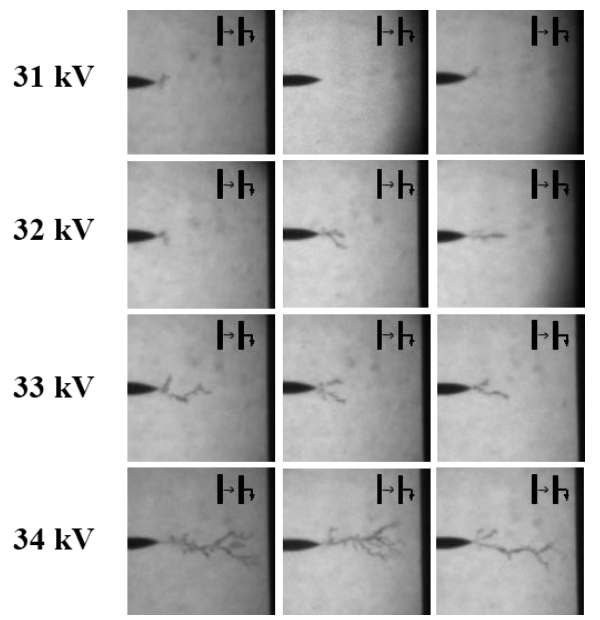

Fig. 4. Typical positive streamer morphologies in semi-uniform field under different voltages, $\mathrm{d}=10 \mathrm{~mm}, \mathrm{~L}=8 \mathrm{~mm}, \mathrm{r}_{\mathrm{p}}=10 \mu \mathrm{m}$.

The influence of field uniformity on streamer propagation can also be revealed from the streamer stopping length which is defined as the straight-line distance from the farthest streamer tip to the needle tip [13]. The streamer stopping lengths against the applied voltage in both fields are plotted in Fig. 5. The gap distances were fixed at $10 \mathrm{~mm}$ in both semiuniform and non-uniform fields. 20 samples were tested under each impulse voltage. The open points and the error bars indicate the mean value and the standard deviation separately. It is clear to see that the streamer stopping length increases as the applied voltage increases in both fields. However, the curve in semi-uniform field is shifted significantly toward higher voltage direction compared to that in non-uniform field. It is harder to initiate the streamer in semi-uniform field since the electric field is more uniform in semi-uniform field with the corresponding field factor reduced to 158 compared with non-uniform field of 246.

The influence of field uniformity on streamer propagation characteristics can also be observed clearly in Fig. 6 plotted in the normalized values. The applied voltage is normalized against the $50 \%$ probability streamer initiation voltage and the streamer stopping length is also normalized to the gap distance $10 \mathrm{~mm}$. The curves tend to be steeper as the electric field becomes uniform with the corresponding field factor decreasing. Such phenomenon is also observed in mineral oil

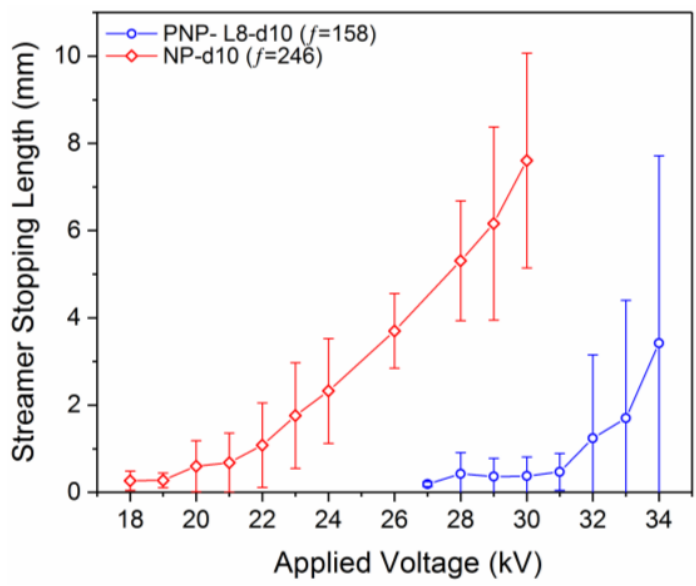

Fig. 5. Relationship between streamer stopping length and applied voltage under NP and PNP geometries, $r_{p}=10 \mu \mathrm{m}$.

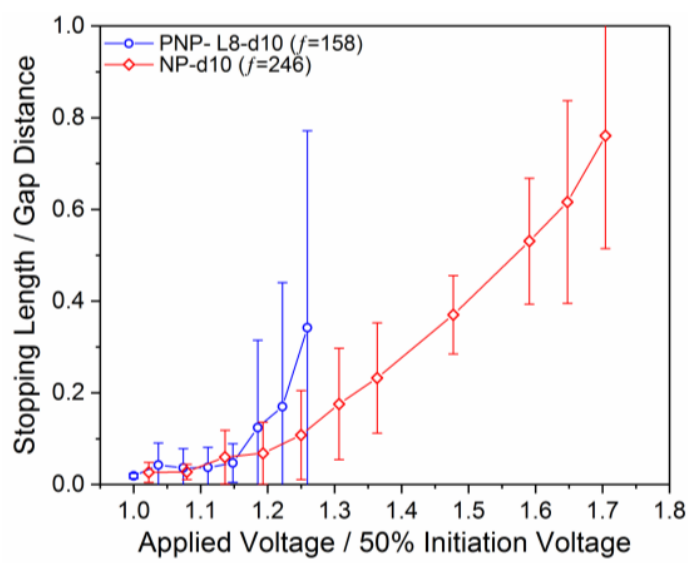

Fig. 6. Normalized stopping length versus normalized applied voltage in GTL oil, $\mathrm{r}_{\mathrm{p}}=10 \mu \mathrm{m}$.

and synthetic ester [9-11]. This could be due to that the streamer propagation would be influenced by the electric field direction. In semi-uniform field, the introduction of the back plane electrode plays shielding effect and weaken the field towards the radial direction [9, 12], which leads to less branches as shown in Fig. 4 compared with non-uniform field. Meanwhile, the propagation of streamer needs energy to sustain. In non-uniform field, the energy is split and dissipated into different radial branches. However, the driving force is mainly focused to direct the discharge head propagating straightforward to the opposite electrode in the semi-uniform field. Hence, the introduction of the back plane electrode facilitates the propagation of streamer in semi-uniform field.

\section{B. Streamer Initiation and Breakdown Voltages}

The streamer initiation voltages and breakdown voltages in the GTL oil were tested and analyzed with 2-parameter Weibull distribution. The statistical results under different electrode geometries are plotted in Fig. 7. The initiation voltages and breakdown voltages with $50 \%$ Weibull probability are calculated and compared with each other. When the gap distance is fixed at $10 \mathrm{~mm}$, the initiation voltage and breakdown voltage are higher under PNP semi-uniform field compared to those under NP non-uniform field. The 50\% probability streamer initiation voltage is improved from 17.6 $\mathrm{kV}$ to $27.0 \mathrm{kV}$, and from $31.0 \mathrm{kV}$ to $36.3 \mathrm{kV}$ for breakdown voltage. At the same time, for NP geometries, both the

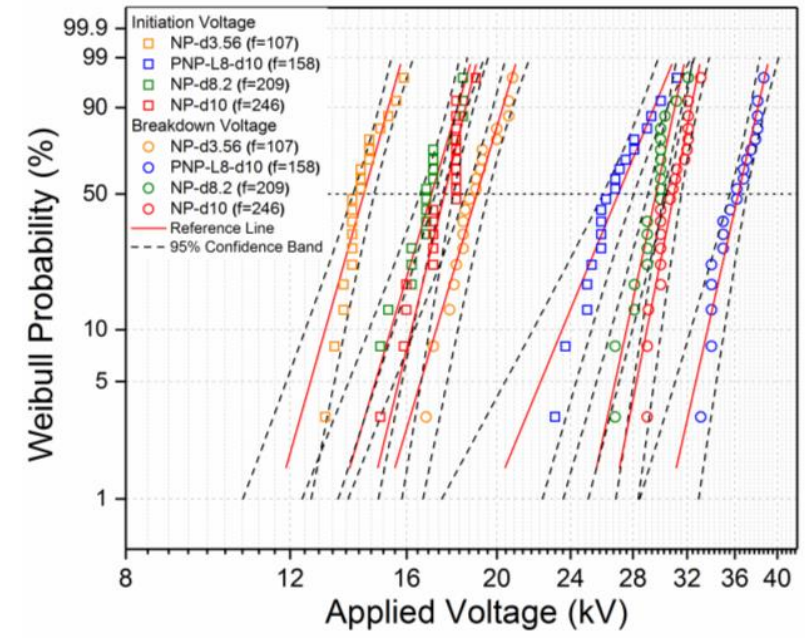

Fig. 7. Streamer initiation voltages and breakdown voltages under different electrode geometries in GTL oil by Weibull distribution. 
initiation voltage and breakdown voltage reduce as the gap distance decreases.

\section{Comparison with Conventional Mineral Oil}

The $50 \%$ probability streamer initiation voltages and breakdown voltages were determined in conventional transformer oil, Gemini $X$, under the same electrode geometries in [11], of which the results are compared with the GTL oil. Both the oils were controlled under dry condition during tests. The comparison of streamer initiation voltages and breakdown voltages between the GTL oil and the mineral oil under the same electrode geometries are presented in Fig. 8 and Fig. 9, respectively. It could be observed clearly that the streamer initiation voltages and breakdown voltages are comparable between the GTL oil and the mineral oil which provide additional reference for the application of GTL oil in power transformers.

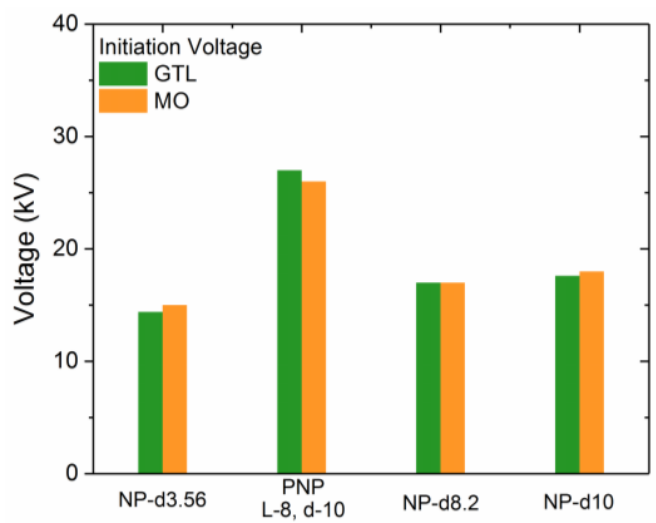

Fig. 8. Streamer initiation voltages comparison between GTL oil and conventional mineral oil under different electrode geometries.

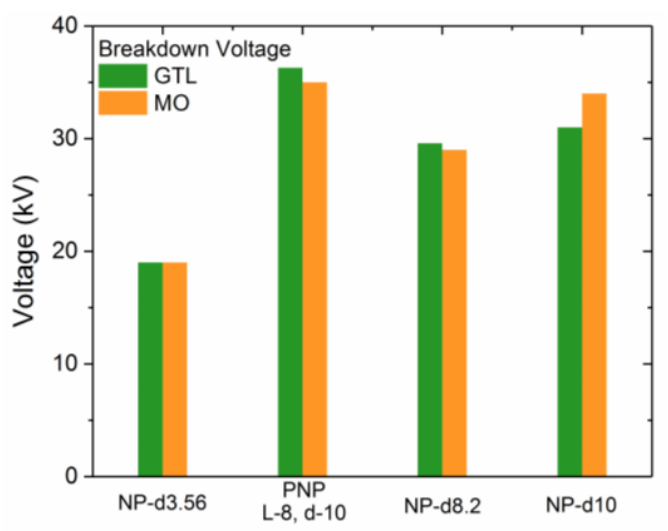

Fig. 9. Breakdown voltages comparison between GTL oil and conventional mineral oil under different electrode geometries.

\section{CONCLUSION}

This paper compares the streamer characteristics of GTL oil under positive lightning impulse between in a planeneedle-plane (PNP) semi-uniform field and a needle-plane (NP) non-uniform field. The streamers propagate farther with increasing applied voltage in both fields. In semi-uniform field, there are less side branches and offshoots and the streamers are mainly restrained along the axial direction compared to the non-uniform field. Meanwhile, the streamer stopping length against normalized applied voltage can also indicate the influence of field uniformity on the streamer characteristics. In semi-uniform field, the streamer propagation is facilitated.
Similar experimental phenomena have been found in mineral oil and synthetic ester. The reason could be due to that the introduction of the back plane electrode in semi-uniform field reduces the electric field towards the radial direction.

The streamer initiation voltages and breakdown voltages were also measured under different field uniformities. When the gap distances are the same, the streamer initiation voltage and breakdown voltage are higher in PNP geometry compared with NP geometry. On the other hand, the streamer initiation voltages and breakdown voltages in the GTL oil are comparable with conventional mineral oil tested previously in [11].

\section{ACKNOWLEDGMENT}

The authors would like to express their gratitude to EPRI, M\&I Materials, National Grid, Scottish Power, SGB-SMIT, Shell, TJ $\mid \mathrm{H} 2 \mathrm{~b}$ and Weidmann for their financial and technical contributions to the Transformer Research Consortium at The University of Manchester.

\section{REFERENCE}

[1] Shell Global. "GAS-TO-LIQUIDS." Retrieved March 2020, https://www.shell.com/energy-and-innovation/natural-gas/gas-toliquids.html, 2020 .

[2] International Electrotechnical Comission, "Power transformers - Part 3: Insulation levels, dielectric tests and external clearances in air," IEC 60076-3, 2018

[3] W. Lu, Q. Liu, Z.D. Wang, and P. W. R. Smith, "Lightning impulse breakdown performance of an inhibited Gas-To-Liquid (GTL) hydrocarbon transformer oil," IEEE 18th International Conference on Dielectric Liquids (ICDL), pp. 1-4, 2014.

[4] W. Lu and Q. Liu, "Prebreakdown and breakdown mechanisms of an inhibited gas to liquid hydrocarbon transformer oil under positive lightning impulse voltage," IEEE Trans. Dielectr. Electr. Insul., vol. 23, pp. 2450-2461, 2016.

[5] W. Lu, Q. Liu, and Z.D. Wang, "Pre-breakdown and breakdown mechanisms of an inhibited gas to liquid hydrocarbon transformer oil under negative lightning impulse voltage," IEEE Trans. Dielectr. Electr. Insul., vol. 24, pp. 2809-2818, 2017.

[6] D. Linhjell, L. Lundgaard, and M. Unge, "Positive third mode streamers in insulating oil," IEEE 19th International Conference on Dielectric Liquids (ICDL), pp. 1-4, 2017

[7] D. Linhjell, L. Lundgaard, M. Unge, and O. Hjortstam, "Prebreakdown phenomena in hydrocarbon liquids in a point-plane gap under step voltage. Part 1: Behaviour at positive polarity," J. Phys. Commun., vol. 4, 2020.

[8] L. Lundgaard, D. Linhjell, O. L. Hestad, M. Unge, and O. Hjortstam, "Pre-breakdown phenomena in hydrocarbon liquids in a point-plane gap under step voltage. Part 2: Behaviour under negative polarity and comparison with positive polarity," J. Phys. Commun., vol. 4, 2020.

[9] S.H. Shen, Q. Liu, and Z.D. Wang, "Positive streamer initiation and propagation in a synthetic ester liquid under lightning Impulse in semiuniform field," 2018 IEEE International Conference on High Voltage Engineering and Application (ICHVE), pp. 1-4, 2018.

[10] S.H. Shen, Q. Liu, and Z.D. Wang, "Effect of field uniformity on positive streamer characteristics of a synthetic ester under lightning impulse," 2019 IEEE 20th International Conference on Dielectric Liquids (ICDL), Roma Italy, pp. 1-4, 2019.

[11] S.H. Shen, Q. Liu, and Z.D. Wang, "Effect of electric field uniformity on positive streamer and breakdown characteristics of transformer liquids," IEEE Trans. Dielectr. Electr. Insul., vol. 26, pp. 1814-1822, 2019.

[12] Z. Liu, Q. Liu, and Z.D. Wang, "Effect of electric field configuration on streamer and partial discharge phenomena in a hydrocarbon insulating liquid under AC stress," J. Phys. D: Appl. Phys., vol. 49, pp. $185501,2016$.

[13] Q. Liu and Z.D. Wang, "Streamer characteristic and breakdown in synthetic and natural ester transformer liquids under standard lightning impulse voltage," IEEE Trans. Dielectr. Electr. Insul., vol. 18, pp. 285294, 2011. 